\title{
HISTOPATHOLOGICAL STUDY ON MICE EXPERIMENTALLY INFECTED WITH S. MANSONI AND TREATED BY NEEM AND MIRAZID
}

\author{
By \\ HANAN TAHER HAMZA ${ }^{1,2^{*}}$, FAYEZ M. SHALDOUM ${ }^{1,3}$, AND \\ WAFAA FAYEZ ABDEL HAMED ${ }^{4}$
}

Department of Biology, College of Science, Jouf University, P.O. Box: 2014, Sakaka, Saudi Arabia ${ }^{1}$, Department of Zoology, Faculty of Science for Girls, Al-Azhar University, Cairo' ${ }^{2}$, and Department of Zoology, Faculty of Science for Boys ${ }^{3}$, and Department of Environmental and Biological Sciences, Faculty of Home Economics ${ }^{4}$, Al-Azhar University ${ }^{3,4}$, Cairo, Egypt ( ${ }^{*}$ Correspondence: dr.h.taher@gmail.com).

\section{Abstract}

Generally, the parasitological markers showed that Neem (Azadirachta indica) and Mirazid (Commiphora molmol, MZ) were effective in reducing worms and eggs of Schistosoma mansoni. This study aimed to detect the histopathological improvement accompanied with using Neem and Mirazid to treat schistosomiasis. A total of 120 Swiss Albino mice were categorized into 10 groups: 5 groups infected with $S$. mansoni and either treated with only Neem (400 $\mathrm{mg} / \mathrm{kg}$ ), only MZ (500mg/kg), a combination of Neem and MZ, praziquantel (PZQ, $200 \mathrm{mg} / \mathrm{kg}$ ) or not treated. Other 5 control groups were not infected but acquired the same treated doses as the above groups. The study was done in Department of Zoology, Faculty of Science, Al-Azhar University, Cairo, Egypt. Hematoxylin eosin and Masson's trichrome stain stained sections were used to examine the histopathological changes in the intestine and liver of mice.

The results showed marked decrease of liver fibrosis in groups of mice treated with neem and/or MZ. This was ensured by a significant diminution in number and diameters of granulomas, reduction in their fibrotic content accompanied with a reduction in total area of infection as compared to infected mice.

Keywords: Schistosomiasis, Commiphora molmol, MZ, Azadirachta indica, liver fibrosis

\section{Introduction}

Schistosomiasis is a very common parasitic infection which affects at least 240 million people worldwide, mostly in Africa. It is regarded as the most frequent cause of liver fibrosis in the world (WHO, 2012; Richter, 2015). Liver fibrosis may be represented by small focal areas of chronic inflammation and excess extracellular matrix deposited in peri ovular granulomas and distributed in variable numbers at the periphery of the portal vein system (Andrade, 2009). One of the most important causes of the non-cirrhotic portal hypertension in Latin America, Africa and Asia was schistosomaisis (Monteiro et al, 2014). The need of a time was searching of a new drug against schistosomiasis and also recommended by the World Health Organization (Stothard et al, 2009). The novel antischistosomal drugs should be discovered and developed (Keiser, 2010). The developing of new antischistosomal agents, trials were designed to test the potency of traditional medicinal plants for treating schistosomiasis. Some of medically important plant species rather gave an effect against schistosomiasis (Kamel et al, 2011). As novel antiparasitic agents, the emergence of parasitic resistance to current chemotherapies highlights the importance of plant essential oils (Etewa and Abaza, 2011). Massoud et al. (2013) reported that Mirazid (Commiphora molmol) is considered as a good clinical improvement with negligible side effects and has side degree of prevalence and spreading not only in Egypt, but worldwide. Its safety and effectiveness was proved in human fascioliasis treatment (Tonkal and Morsy, 2008) and schistosomiasis (ElSayed et al, 2017). Neem (Azadirachta indi$c a$ ) has been bioactive ingredients and other biological activities possessing anti-allergenic, antiemetic, anti-feeding, anti-viral, antifungal, anti-inflammatory, anti-pyorrhoeic, anti-scabitic, insecticidal, parricidal, anti-implantation, nematicidal, and spermatocidal 
(Ogbuewu et al, 2011; Sonhafouo et al, 2019). Many antiparasitic extracts are used as methanol leaf and stem bark extracts of $E$. ivorense were successively fractionated with acetone against the somules, also Papaya carica fruit extracts are rich with phenolic acids and flavonoids and show a significant effect against $S$. mansoni infections, it is recognized to offer different therapeutic purposes of premium where decreased worm burden, immature ova and mature ova, while increa- sing the percentage of dead ova in vivo (Anjana et al, 2018). Host-parasite interactions in schistosomiasis help in understanding many important facts of the liver fibrosis (Andrade, 2009). The inflammatory granuloma formation around deposited eggs; granulomas were composed of macrophages, eosinophils and lymphocytes with proportion of cells varied in different organs characterizing schistosomiasis (Abdel-Lateef et al, 2018). Granuloma formation is a cellmediated immune response dependent on CD4+ T cells sensitized to schistosomal egg antigens. The $\mathrm{T}$ cell-mediated granulomatous response gets to the peak between $8 \&$ 10 weeks after exposure in mice. This acute stage granuloma is characterized by dense cellularity and maximum cytokine production. While the fibrotic components of the immunopathologic process increase, the infection progresses into the chronic stage (1620 weeks post infection), cytokine production and cellularity decrease (Chesney et al, 1998). Chronic liver disease of schistosomiasis (HSS) characterized by granulomatous reaction with excess collagen deposition, portal fibrosis, pre-sinusoidal portal hypertension, splenomegaly or hypersplenism, esophageal varices and hemorrhage (Zimmon and Kessler, 1980). Using praziquantel administered to 100 million people every year and less sensitive strains have already been isolated from those peoples. This led to the administration of large amount of drug (Doenhof et al, 2008). The effects of praziquantel given twice a year as annual or biennial regimens on the prevalence and intensity of schistosomiasis was reported (Obonyo et al, 2019). Intestinal granulomas in the colon and small intestine of mice are smaller than those in the liver and they are not always subject to the same down regulation and are associated with less fibrosis than are hepatic granulomas. Alterations in the vasculature and innervation of the intestines of infected mice were reported (Jacobs et al, 1998). Death of intestinal neurons was uncommon, in spite of the predominance of small intestinal over colonic pathology in infected mice and the evident gross and microscopic lesions (Nassauw et al, 2001).

The current investigation showed marked decrease of liver fibrosis in the groups of mice treated with Neem and/or MZ. Hepatic pathogenesis and granuloma diameter were assessed in an attempt to study the effect of treatment with plant extract on the infected mouse model. This was ensured by significant diminution in number and diameters of granulomas, reduction in their fibrotic content accompanied with a reduction in total area of infection as compared with infected mice. Treatment of infected mice with the current used plant extracts either alone or in combination improved the histopathological picture of intestine and liver. Hepatic pathogenesis and granuloma diameter were assessed in an attempt to study the effect of treatment with plant extract on the infected mouse model.

\section{Materials and Methods}

Parasites and infection: Swiss male Albino mice were used in this study, aged 6 weeks old and weighing 20-25gms. Cercariae of $S$. mansoni Egyptian strain were purchased from the Schistosome biological supply center, Theodore Bilharz Research Institute (TBRI), Imbaba, Giza, Egypt and used for infection immediately after shedding from Biomphalaria alexandrina. Each mouse was infected with $60 \pm 10$ cercariae/mouse by subcutaneous injection (Christopherson, 1918). The infected mice were randomly chosen and divided into main five groups and maintained with pellets food and water. The mice 
were allowed to adapt to the laboratory environment for one week before experiment.

A total of 120 Swiss Albino mice were divided into 10 groups. Five were infected with $S$. mansoni. Group 1 (G1) was treated with Neem extract, $A$. indica $(400 \mathrm{mg} / \mathrm{kg})$ at 4 weeks post infection (I.P) to represent adult worm respectively. The extract was given orally by gastric gavage once a day for 5 consecutive days using an oral volume of $0.4 \mathrm{ml} \mathrm{A}$. indica/mouse. In group 2 (G2) only $\mathrm{MZ}(500 \mathrm{mg} / \mathrm{kg} /)$ was given orally at 4week post infection (I.P) for 5 consecutive days. Mirazid ${ }^{\circledR}$ was obtained as oleoresin extract in capsules produced by Pharco Pharmaceuticals Co. The desired concentration of extract was dissolved in dimethyl sulfoxide (DMSO, Sigma) (Ogbuewu et al, 2011). The third group (G3) was treated with a combination of Neem and MZ while the fourth group (G4) was treated with Praziquantel $^{\circledR}$ (PZQ, 200mg/kg). Discoid or PZQ was purchased from the Egyptian International Pharmaceutical Industries Co. (EPICO) given orally (for first day of 7 weeks) in a dose of $200 \mathrm{mg} / \mathrm{kg}$ body weight/ day in a dose volume of $0.05 \mathrm{ml}$ for 5 consecutive days to a total dosage of $1000 \mathrm{mg} / \mathrm{kg}$ (Ahmed and Ahmed, 2003). The last group (G5) was infected and untreated group. The other five groups were not infected but were given the same treatment doses as the infected ones (control groups). Another, ten healthy mice were used as normal control group and all mice were sacrificed on the $7^{\text {th }} \& 9^{\text {th }}$ weeks post infection and were subjected to:-

Liver perfusion: All groups of mice were sacrificed ( 3 weeks post treatment) by injecting them with $0.25 \mathrm{ml}$ of heparinized sodium pentobarbitone intra-peritoneal to euthanize them and the worms recovered through perfusion of liver and mesenteric veins (Utzinger et al, 2002). Liver and intestine were recovered from the perfused mice. Recovered worms were collected in petridishes and enumerated under a dissecting microscope. Worms were fixed in $10 \%$ alcohol solution for the histological studies.
Histological and histochemical study: Tissues (intestine \& liver) were collected from each group, dissected and processed for light microscope examination. Specimens were fixed in $10 \%$ neutral buffered formol solution and Carnoy's fluid for the histological and histochemical studies. They were processed to prepare $4 \mu \mathrm{m}$ thick paraffin sections and stained with Harris haematoxylin and eosin (H \&E) (Bancroft and Gamble, 2002). Collagen was detected by Masson's Trichrome stain (Pearse, 1977).

Granuloma measurements: Counting of granulomas within a set area of sections and the number of granulomas per $\mathrm{cm}^{2}$ was calculated (Lepta and Mc-Kerrow, 1997). Also, the granulomas diameter was measured by using Q Capture Pro software.

\section{Results}

Microscopic examination of adult worms extracted from both infected not treated and infected, treated mice showed some morphological changes as malformation and degeneration of internal structures or elongation of the worm and rupture of degenerated of internal structures in females, while Males recovered from treated mice showed malformation in testes or elongations (Figs. 1,2).

Histopathological and histochemical studies: 1- Intestine sections of mice treated by Neem showed the least number of eggs in the submucosa associated with inflammatory cell infiltration. Mice treated by Mirazid and Neem showed granuloma formation while mice treated by Mirazid only showed necrosis in the villi and submucosal granuloma formation. Mice treated by PZQ showed eggs in submucosa associated with inflammatory cell infiltration. Many eggs of were detected in the submucosa associated with inflammatory cells infiltration, while sections in intestine of mice treated by Neem, or Mirazid and Neem, or Mirazid only, or DMSO or PZQ showed no histopathological changes (Figs. 3,4,5,6). 2- Liver sections of mice treated by Neem showed intravascular eggs surrounded by inflammatory cell infiltration. Mice treated by Mirazid and Neem 
showed portal infiltration with massive inflammatory cells. Mice treated by Mirazid showed granuloma formation. The intravascular multiple eggs surrounded by inflammatory cells and fibroblasts (large arrow). All agents showed reduction of granuloma and a marked infiltration of lymphocytes. Mice treated by PZQ showed intravascular eggs surrounded by inflammatory cells and granuloma size reduction with disintegrated central eggs and group 5 (infected mice) showed large focal hepatic necrosis markedly infiltrated with inflammatory cells while liver sections of treated mice from C1, C2, C3, C4 showed Kupffer cells activation with slight vacuolation of hepatocytes in PZQ treatment (Figs. 7, 8, 9). 3- Intestinal sections: Mice treated with Neem or Neem \& Mirazid showed moderate positive histochemical reaction for collagen fibers, and significantly increased glycogen amount in the goblet cells. Thin granules of glycogen were positively stained, while group 5 showed strong positive histochemical reaction for collagen fibers. On the other hand, intestinal sections of mice treated by Neem only, or Mirazid and Neem, or Mirazid only or and PZQ showed no histochemical reactions (Figs. 6,7). Liver sections of mice in all infected and treated groups showed strong positive histochemical reaction for collagen fibers. But, liver sections of treated control mice groups showed no histochemical reaction.

Granuloma measurements showed marked decrease of liver fibrosis in the groups of mice treated with Neem and/or MZ. This was ensured by significant diminution in number and diameters of granulomas, reduction in their fibrotic content accompanied with a reduction in total area of infection as compared with untreated infected livers mice by $74.47 \%, 31.85 \%(\mathrm{P} \leq 0.01, \mathrm{P} \leq 0.05)$ in comparison with the untreated infected group.

Details were given in table (1), chart (1) and figures $(1,2,3,4,5,6,7,8, \& 9)$

Table 1: Parasitological parameters after treatment of $S$. mansoni infected mice with different supplementations:

\begin{tabular}{|l|c|c|c|c|}
\hline \multicolumn{1}{|c|}{ Items } & $\begin{array}{c}\text { Granuloma in liver } \\
\text { LPF }\end{array}$ & Protection\% & $(\mu \mathrm{m})$ Granuloma diameter & Protection\% \\
\hline Neem group G1 & $21.00 \pm 1 \#$ & $32.98 \%$ & $337.39 \pm 34.22^{* *}$ & $31.85 \% *$ \\
\hline Mirazid+neem G3 & $8.00 \pm 1 * *$ & $74.47 \% * *$ & $419.42 \pm 62.97 \#$ & $15.28 \%$ \\
\hline Mirazid only G2 & $22.00 \pm 1 \#$ & $29.78 \%$ & $354.89 \pm 61.70^{*}$ & $28.31 \%$ \\
\hline PZQ G4 & $32.30 \pm 3.21 \#$ & $-3.09 \%$ & $439.08 \pm 58.57 \#$ & $11.31 \%$ \\
\hline Control (infected) G5 & $31.33 \pm 10.02$ & & $495.09 \pm 61.89$ & \\
\hline
\end{tabular}

Data $=\mathrm{M} \pm \mathrm{SD}$ of 10 mice in each group. LPF: Low power microscope $(\times 100) . * * \mathrm{P} \leq 0.01,{ }^{*}$ at $\mathrm{P} \leq 0.05$, \# non-significant when compared with infected group.

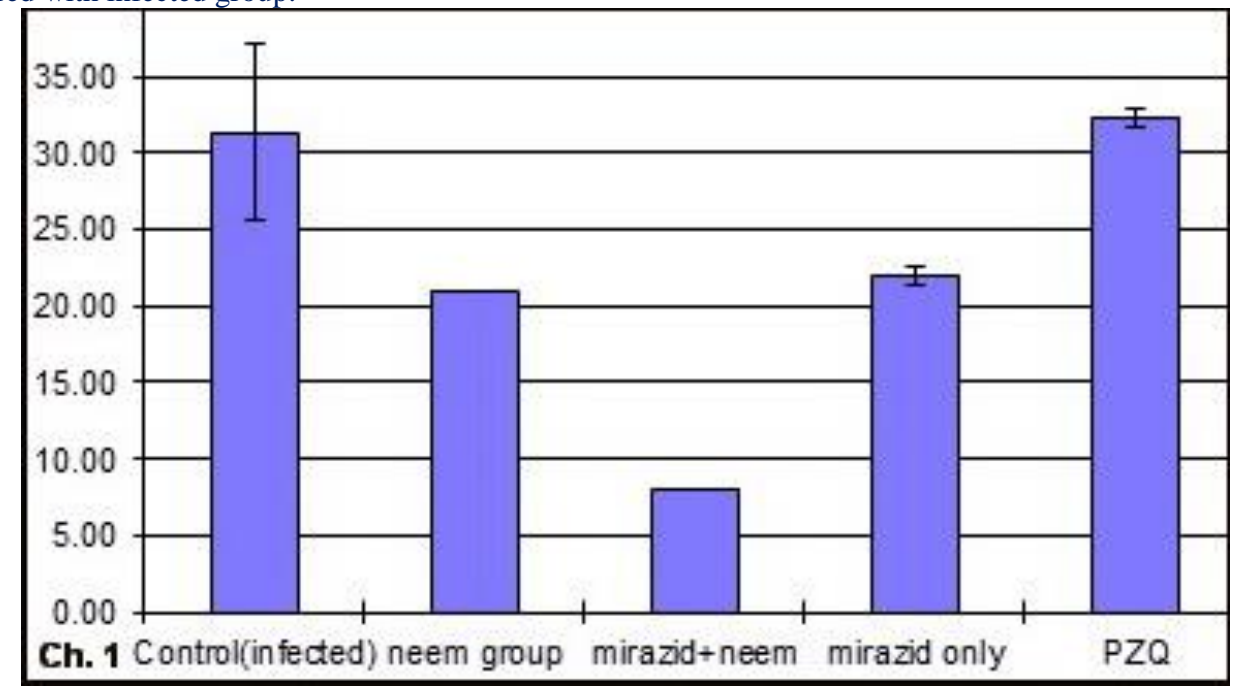

Chart 1: Effect of Neem or Mirazid extract on number of granulomata in S. mansoni infected mice. 


\section{Discussion}

Human schistosomiasis is an acute and chronic water-borne parasitic disease, caused by infection with trematode worms of the genus Schistosoma. In 2017, more than 220 million people were infected (WHO, 2018). Schistosomiasis remains an important cause of liver disease in areas of frequent transmission and presents as a challenge to diagnosis in non-endemic areas. Detection of active infection and staging of liver disease are the main goals in schistosomiasis management (Cavalcanti et al, 2015).

Morphological changes of the adult worms extracted from both infected non treated or infected and treated mice revealed malformation and degeneration of internal structures or elongation of the worm and rupture of degenerated of internal structures in female worms, while adult male worms recovered from treated mice showed malformation in number of tests or elongation of the worms which agreed with Sanad and Al Furaeihi (2006) and Massoud et al. (2013). The present results showed that exposure of the worm surface antigen leading to attraction of inflammatory cells like neutrophils and eosinophils which attack the worms, so worm expulsion can be explained by excessive production of mucus which traps the worms leading to expulsion of them from the small intestine and the worms have to utilize more energy to break the sticky mucin to move into a more desirable region of the intestine; this reflects the decreased biomass of worms where goblet cells and mucin secretion were higher, these agreed with Doenhoff et al. (2008), Elliott et al. (2011) and Mazigo et al. (2019).

Host-parasite interactions in schistosomiasis help to understand a number of important features of liver fibrosis: its initiation and regulation, the significance of accompanying vascular changes, the dynamics of fibrosis formation and regression with antiparasitic treatment; host genetic and immunological contributions and the pathophysiology of portal hypertension (Andrade, 2009).
The current study demonstrated that $A$. indica extract possesses strong schistosomicidal activity against $S$. mansoni adult worms (Female and male worms). One of the major pathological features of $S$. mansoni parasites is their ability to persist and establish a chronic infection. This leads to chronic inflammation, which in turn can lead to severe fibrotic modification of infected tissues and organs (Meneghin and Hogaboam, 2007). Intestine granulomas in the colon and small intestine of mice were smaller than those in the liver, are not always subject to the same down-regulation and were associated with less fibrosis than hepatic granulomas. Alterations in the vasculature and innervation of the intestines of infected mice have been reported (Jacobs et al. 1998). Death of intestinal neurons was uncommon (Nassauw et al, 2001). Despite predominance of small intestinal over colonic pathology in infected mice and the evident gross and microscopic lesions, the functional changes seem slight.

The present results showed that in groups G1, G2 there was a moderate positive histochemical reaction for collagen fibers, while groups G3, G4 \& G5 showed strong positive histochemical reaction for collagen fibers. Fibrosis results when the rate of collagensynthesis is higher than that of collagen deggradation (Chen et al, 2002).

Plant extract and the combination of all supplementations were the most effective ones revealing their anti-fibrotic effect that extract could be attributed to its active compounds. These results agreed with El-Naggar (2007); Keiser (2010) and Kamel et al. (2011). Neem only or in combination with Mirazid exhibited hepato-protective activity, anti-inflammatory and inhibitory effect on liver fibrosis. The results agreed with Wang et al. (2012). Previous investigations revealed that non-immunologic and immunologic mechanisms play a central role in liver fibrosis (Mohamed et al, 2008). Also, the present results recorded an improvement in histological picture of the liver of $S$. mansoni infected mice which was treated with 
Mirazid extract. None infected animal which received Mirazid extract showed normal histological picture which proved that $C$. molmol was effective as an anti-inflammatory drug; the present results coincide with Massoud et al. (2010). Previous study revealed that the intensity of schistosomal infection which was represented by the worm burden and egg count increased the degree of liver fibrosis and granulomatous reaction (El-Lakkany et al, 2004). The current investigation showed marked decrease of liver fibrosis in the groups of mice treated with Neem and/or MZ. This was ensured by a significant diminution in number and diameters of granulomas, reduction in their fibrotic content and accompanied by reduction in total area of infection as compared to untreated infected livers mice $(74.47 \%, 31.85 \%)$ respectively. This agrees with Rollino et al. (2008) and Bakry and Ismail (2017).

Treatment of infected mice with the current used plant extracts either alone or in combination improved the histopathological picture of intestine and liver. This agrees with the present histopathological findings of infected untreated mice liver which showed increased number and diameter of granuloma, total area of infection and extensive fibrous tissue accumulation. In the present study, infected mice treated with plant extract either alone or in combination improved the liver histopathology. This was ensured by significant diminution in number and diameters of granulomas, reduction in their fibrotic content accompanied by a reduction in total area of infection as compared to infected mice (Chen et al, 2002). Mokua et al. (2013) proved a reduction in granuloma formation by using Papaya carica methanol and aqueous extracts, pointing to an immune response, which either sterilized the females that they could not lay eggs, or reduced the granulomas. Granuloma formation in the liver was the worst in infected-untreated control group while; Praziquantel had the lowest granuloma formation level. Although Praziquantel was the most efficacious drug, some mice under this treatment had granulomas. This was due to the fact that some parasites have delayed maturation and thus escaped the Praziquantel effect at the administration time. Praziquantel drug has a short half-life of 1-1.5 hours and not effective against schistosomules (Doenhoff et al, 2009), as well as in-vivo, it showed hepatotoxic, genotoxic and carcinogenic effects (Omar et al, 2005).

Treatment of infected mice with PZQ improved the liver histopathological picture ensured by significant diminution in number and diameters of granulomas compared to infected untreated mice. This agreed with Chaiworaporn et al. (2005). Most pathology in schistosome infected animals is attributed to the host's reaction to the eggs which is maximal by the $8^{\text {th }}$ wk of infection. Natural killer cells may comprise over $20 \%$ of cells in granuloma, but produced little IFN- $\gamma$ (Rakasz et al, 1998).

Chesney et al. (1998) described the infiltration of circulating "fibrocytes" into granulomas and speculate that these cells may be important for attracting CD4+ lymphocytes as well as for collagen formation. After the $8^{\text {th }}$ wk of infection; there was down modulation of the immune reaction and granulomas around recently deposited eggs which became progressively smaller. Schistosomiasis manifestations were mainly attributed to granulomatous inflammation around the parasite eggs (Abath et al, 2006). The granulomas formation depends on CD4+ T cell specific for egg antigen and represented delayed type hypersensitivity (Mann and Mann, 2009). Bakry and Ismail (2017) elucidated the potential of the plant extract of Phoenix dactylifera and Zingiber officinale plants in treating Schistosoma mansoni infected mice. Histological changes in liver tissues of infected and treated with Phoenix dactylifera mice were studied and showed small sized fibro-cellular granuloma with degenerated ova and less inflammatory cells. Liver sections from the infected group treated with Zingiber officinale showed a reduction in granuloma size and marked fragmentation of 
the ovum inside the granuloma. All treated group showed significant granuloma diameter diminution, and all regimens significantly increased of dead ova percentage of in liver compared to infected untreated ones. This agreed with Rollino et al. (2008).

\section{Conclusion}

Treatment of $S$. mansoni infected mice with plant extracts (Mirazid and Neem) significantly reduced both worm burden and egg production and improve liver histology, with remarkable healing of hepatic granulomatous lesions as compared to normal healthy controls.

Moreover, these plant extracts recorded a significant diminution in number and diameters of granulomas as well as reduction in their fibrotic content. Plant extracts can be added as a potential treatment against schistosomiasis together with the anti-schistosomal drug praziquantel. These combined of these two regimens will minimize the praziquantel dose and increase the effectiveness of treatment.

\section{References}

Abath FG, Morais CN, Montenegro, CE, Wynn, TA, 2006: Montenegro SM Immunopathogenic mechanisms schistosomasis: what can be learnt from human studies? Trends Parasitol. 22: 85-91.

Abdel-Lateef, EE, Rabia, I A, El-Sayed, M M, Abdel-Hameed, ES, 2018: HPLC-ESI-MS characterization of certain polyphenolic compounds of Papaya carica L. fruit extracts and evaluation of their potential against murine schistosomiasis mansoni. Drug Res. 68, 9:521-8.

Ahmed, AAM, Ahmed, SM, 2003: Extracts of leaves and seeds of the Neem tree, Azadirachta indica, as environment-oriented molluscicides for combating schistosomiasis. Proceedings of Workshop on African Freshwater Malacology, Kampala, Uganda.

Andrade, ZA, 2009: Schistosomiasis and liver fibrosis. Parasite Immunol. 31, 11:656-63.

Anjana, GV, Priya, D, Srimathi, R, Shantha, B, 2019: A review on medical advantages and chemical constituents of Carica Papaya Linn. Asian J. Pharm. Clin. Res. 11, 9: 53-7.

Bakry, FA, Ismail, SM, 2017: Impact of plant extracts on parasitological and histological pa- rameters of Albino mice infected with Schistosoma mansoni. J. Biomater. 1, 1:10-8.

Bancroft, JD, Gamble, M, 2002: Theory and Practice of Histological Techniques. $5^{\text {th }}$ Ed., Churchill Livingstone, London.

Cavalcanti, MG, Araujo-Neto, JM, Peralta, JM, 2015: Schistosomiasis: Clinical management of liver disease. Clin. Liver Dis. 6, 3:59-62.

Chaiworaporn, R, Maneerat, Y, Rojekitkhun, W, Ramasoota, P, Janecharut, T, et al, 2005: Therapeutic effect of subcurative dose praziquantel on Schistosoma mansoni infected mice and resistance to challenge infection after treatment. Southeast Asian J. Trop. Med. Publ. Hlth. 36, 4:846-52.

Obonyo CO, Muok EMO, Vincent, W, 2019: Biannual praziquantel treatment for schistosomia sis: Cochrane Library Cochrane Database of Systematic Reviews; Issue 8, Art. No.: CD013412. Chen, F, Cai, W, Chen, Z, Chen, X, Liu, R, 2002: Dynamic changes in the collagen metabolism of liver fibrosis at the transcription level in rabbits with schistosomiasis japonicum. Chin. Med. J. 115:1637-40.

Chesney, J, Metz, C, Stavitsky, AB, Bacher, M, Bucala, R, 1998: Regulated production of type I collagen and inflammatory cytokines by peripheral blood fibrocytes. J. Immunol. 160: 419-25.

Christopherson J, 1918: Intravenous injection of antimonium tartaratum in bilharziosis. Brit. Med. J. 2:652-8.

Doenhoff, M, Cioli, D, Utzinger, J, 2008: Praziquantel: mechanisms of action, resistance and new derivatives for schistosomiasis. Curr. Opin. Infect. Dis. 21:659-67.

Doenhoff, MJ, Hagan, P, Cioli, D, Southgate, V, Pica-Mattoccia, L, et al, 2009: Praziquantel: Its use in control of schistosomiasis in subSaharan Africa and current research needs. Parasitology 13:1-11.

Doenhoff, MJ, Cioli, D, Utzinger, J, 2008: Praziquantel: Mechanisms of action, resistance and new derivatives for schistosomiasis. Curr. Opin. Infect. Dis. 21, 6:659-68.

El-Lakkany NM, Seif El-Din SH, Badawy A A, Ebeid FA, 2004: Effect of artemether alone and in combination with grape fruit juice on hepatic drug-metabolizing enzymes and biochemical aspects in experimental Schistosoma mansoni. Int. J. Parasitol. 34:1405-12.

Elliott, AM, Ndibazza, J, Mpairwe, H, Muh- 
angi, L, Webb, EL, et al, 2011: Treatment with anthelminthics during pregnancy: what gains and what risks for the mother and child? Parasitology 138, 12:1499-507.

El-Naggar, SA, 2011: Lack of the beneficial effects of mirazid (Commiphora molmol) when administered with chemotherapeutic agents on ehrlich ascetic carcinoma bearing mice. Adv. Biol. Res. 5, 4:193-9.

El-Sayad, M, Abu-Helw, S, El-Taweel, H, Aziz, M, 2017: Antiparasitic activity of mirazid, myrrh total oil and nitazoxanide compared to praziquantel on Schistosoma mansoni: scanning electron microscopic study. Iran. J. Parasitol. 12, 3:446-52.

Etewa, SE, Abaza, SM, 2011: Herbal medicine and parasitic diseases. P.U.J. 4, 1:3-14.

Humphrey, D, Mazigo, HD, Owuocha, S, Paulina, M, Deodatus, R, et al, 2019: Praziquantel Treatment is recommended: Active Schistosoma mansoni infection among patients diagnosed with oesophageal varices at a Tertiary Referral Hospital, North-Western Tanzania. Ann. Short Reports Neurol. 2, 1035:1-3.

Jacobs, W, Bogers, JJ, Timmermans, JP, Deelder, AM, Van Marck EA, 1998: Adhesion molecules in intestinal Schistosoma mansoni infection. Parasitol. Res 84: 276-280.

Kamel, EG, El-Emam, MA, Mahmoud, SSM, Fouda, FM, Bayaumy, FE, 2011: Parasitological and biochemical parameters in Schistosoma mansoni-infected mice treated with methanol extract from the plants Chenopodium ambrosioides, Conyza dioscorides and Sesbania sesban. Parasitol. Int. 60:388-92.

Keiser, J, 2010: In vitro and in vivo trematode models for chemotherapeutic studies. Parasitol. 137:589-603.

Leptak CL, McKerrow JH, 1997: Schistosome egg granulomas and hepatic expression of TNF-alpha are dependent on immune priming during parasite maturation. J. Immunol. 158: 301-7.

Mann J, Mann DA, 2009: Transcriptional regulation of hepatic stellate cells. Advanced drug delivery reviews 61: 497512.

Massoud, AM, Shalaby, HA, El Khateeb, R M, Mahmoud, MS, Kutkat, MA, 2013: Tegumental histological effects of Mirazid and myrrh volatile oil on adult Fasciola gigantica. Asian Pac. J. Trop. Biomed. 3, 6:501-4.

Massoud, AM, El-Sherbini, ET, Saleh, NMK,
Abou El-Nour, MF, Morsy, ATA, 2010: Mirazid treatment of three zoonotic treamatods in Beni-Swif and Dakhalia Governorates. J. Egypt. Soc. Parasitol. 40, 1:119-34.

Meneghin, A, Hogaboam, CN, 2007: Infectious disease, the innate immune response, and fibrosis. J. Clin. Invest. 117, 3:530-8.

Mohamed, AM, Mahmoud, SS, AFarrag, AA, 2008: Influence of Sativa seeds against liver fibrosis and consequence complications in murine schistosomiasis. Int. J. Biotechnol. Biochem, 4: 325-46.

Mokua, JM, Helen, K, Rebecca, W, Dorcas, Y, 2013: Evaluating the antischistosomal activity of crude extracts of Carica papaya against Schistosoma mansoni: The interplay of cellular and humoral immunity. J. Biomed. Pharm. Res. 2, 1:33-41.

Monteiro, WM, Franca, GP, Melo, GC, Queiroz, ALM, Marcelo Brito, M, et al, 2014: Clinical complications of G6PD deficiency in Latin American and Caribbean populations: systematic review and implications for schistosomiasis elimination programmes. Schistosomiasis J. 13:70-9.

Nassauw L van, Bogers J, Van Marck E, Timmermans JP, 2001: Role of reactive nitrogen species in neuronal cell damage during intestinal schistosomiasis. Cell Tissue Res 303: 329-36.

Ogbuewu, IP, Odoemenam, VU, Obikaonu, H O, Opara, MN, Emenalom, OO, et al, 2011: The growing importance of Neem (Azadirachta indica) in agriculture, industry, medicine and environment: A review research. J. Med. Plant 5: 230-45.

Omar, A, Elmesallamy, GE, Eassa, S, 2005: Comparative study of the hepatotoxic, genotoxic and carcinogenic effects of praziquantel distocide \& the natural myrrh extract Mirazid on adult male albino rats. J. Egypt. Soc. Parasitol. 35, 1:313-29

Pearse, AG, 1977: Histochemistry: Theoretical and Applied. $3^{\text {rd }}$ Ed., Livingstone, London.

Rakasz, E, Blum, AM, Metali, A, Elliot, DE, Li, J, et al, 1998: Localization and regulation of IFN- $\gamma$ production within the granulomas of murine schistosomiasis in IL-4-deficient and control mice. J. Immunol. 160:4994-9.

Richter, J, Bode, JG, Blondin, D, Kircheis, G, Kubitz, R, et al, 2015: Severe liver fibrosis caused by Schistosoma mansoni: Management and treatment with a transjugular intrahepatic porto- 
systemic shunt. Lancet Infect. Dis. 15, 6:731-7. Rollino, C, Guzman, H, Beltrame, G, Ferro, M, Quattrocchio, G, et al, 2008: Retroperitoneal fibrosis and schistosomiasis: A causal relation -ship? Euro J. Inter. Med., 19:297-9.

Sanad, MM, Al Furaeihi, LM, 2006: Effect of some imunomodulators on the host-parasite system in experimental Hymenolepis nana. Egypt. J. Med. Sci. 36, 1:65-80.

Sonhafouo, VM, Kana, JR, Dongmo, KN, 2019: Effects of graded levels of Azadirachta indica seed oil on growth performance and biochemical profiles of broiler chickens Vet. Med. Sci. 5, 3:442-50.

Stothard, JR, Chitsulo, L, Kristensen, TK, Utzinger, J, 2009: Control of schistosomiasis in sub-Saharan Africa: Progress made, new opportunities and remaining challenges. Parasitol. 136, 13:1665-75

Tonkal, AMD, Morsy, TA, 2008: An update review on Commiphora molmol and related species. J. Egypt. Soc. Parasitol. 38, 3:763-96.

Utzinger, J, Chollet, ZW, Tu, S, Xiao, H, Tanner, M, 2002: Comparative study of infected mice. Trans. R. Soc. Trop. Med. Hyg, 96:31823.

Wang, H, Weng, H, Feigenbum, L, Li, H, Yin, $\mathrm{S}$, et al, 2011: In vivo consequences of liverspecific interleukin-22 expression in mice: Implications for human liver disease progress- ion: Liver Biol. Pathobiol. Hepatol. 54, 1:252-61.

WHO, 2012: Scistosomiasis. Available at http:// www.who.int/mediacentre/facesheets/fs115/en/ . WHO, 2018: Schistosomiasis and soil-transmitted infections number of people treated in 2017. Wkly. Epidemiological Record 93:681-92. Zimmon, DS, Kessler, RE, 1980: Effect of por tal venous blood flow diversion on portal pressure. J. Clin. Invest. 65:1388-97.

\section{Explanation of figures}

Fig 1: Adult females recovered from mice treated with Neem (G1). Mirazid and Neem (G2) showed normal appearance of internal structure. Mirazid (G3) showed malformed and degenerated of internal structures (a), long female (b), malformation, elongation of worm and rupture of degenerated of internal structures(c). PZQ (G4) showed long female, infected mice G5 showed normal appearance (a, b, c).

Fig 2: Adult males recovered from mice treated with Neem (G1) showed reduced number of testes. Mirazid and Neem (G2) showed normal number and appearance of testes. Mirazid (G3) showed long male and reduced number of testes. PZQ (G4) showed reduced number of testes and infected mice (G5) showed normal worms appearance.

Fig. 3: Intestinal sections of mice treated by Neem (G1) showed least number of eggs in submucosa associated with inflammatory cells infiltration, (G2) mice treated by Mirazid and Neem showed granuloma formation, (G3) mice treated by Mirazid showed necrosis of villi and submucosal granuloma formation, (G4) mice treated by PZQ showed eggs in submucosa associated with inflammatory cells infiltration and (G5) infected mice showed granuloma formation. Multiple eggs in submucosa associated with inflammatory cells infiltration (H \& E, X100). Fig. 4: Intestinal sections of mice treated by Neem C1, Mirazid and Neem C2, Mirazid C3, DMSO C4 \& PZQ C5 showed no histopathological changes $(\mathrm{H} \& \mathrm{E}, \mathrm{X} 100)$

Fig. 5: Intestinal sections of mice, Note G1, G3 showed moderate positive histochemical reaction for collagen fibers, while (G3), (G4) \& (G5) showed strong positive histochemical reaction for collagen fibers (Masson's Trichrome stain, X100).

Fig. 6: Intestinal sections of mice treated by Neem C1, Mirazid and Neem C2, Mirazid C3, DMSO C4 \& PZQ group C5 showed no histochemical reaction for collagen fibers (Masson's Trichrome stain, X100).

Fig. 7: Liver sections of mice treated by Neem (G1) showing intravascular eggs surrounded by inflammatory cells infiltration, (G2) mice treated by Mirazid and Neem showed portal infiltration with massive inflammatory cells, (G3) mice treated by Mirazid showed granuloma formation. Intravascular multiple eggs (small arrow) surrounded by inflammatory cells and fibroblasts (large arrow), (G4) mice treated by PZQ showed intravascular eggs (small arrow) surrounded by inflammatory cells (large arrow) and (G5) infected mice showed large focal hepatic necrosis markedly infiltrated with inflammatory cells (H \& E, X400).

Fig 8: Liver sections of treated mice from C1, C2, C3, C4 showed Kupffer cells activation and slight vacuolation of hepatocytes in PZQ C5 ( $\mathrm{H} \& \mathrm{E}, \mathrm{X} 400)$.

Fig 9: Liver sections of mice, group 1, 2, 3, 4, \& 5 showed strong positive histochemical reaction for collagen fibers (Masson's trichrome stain, X400). 


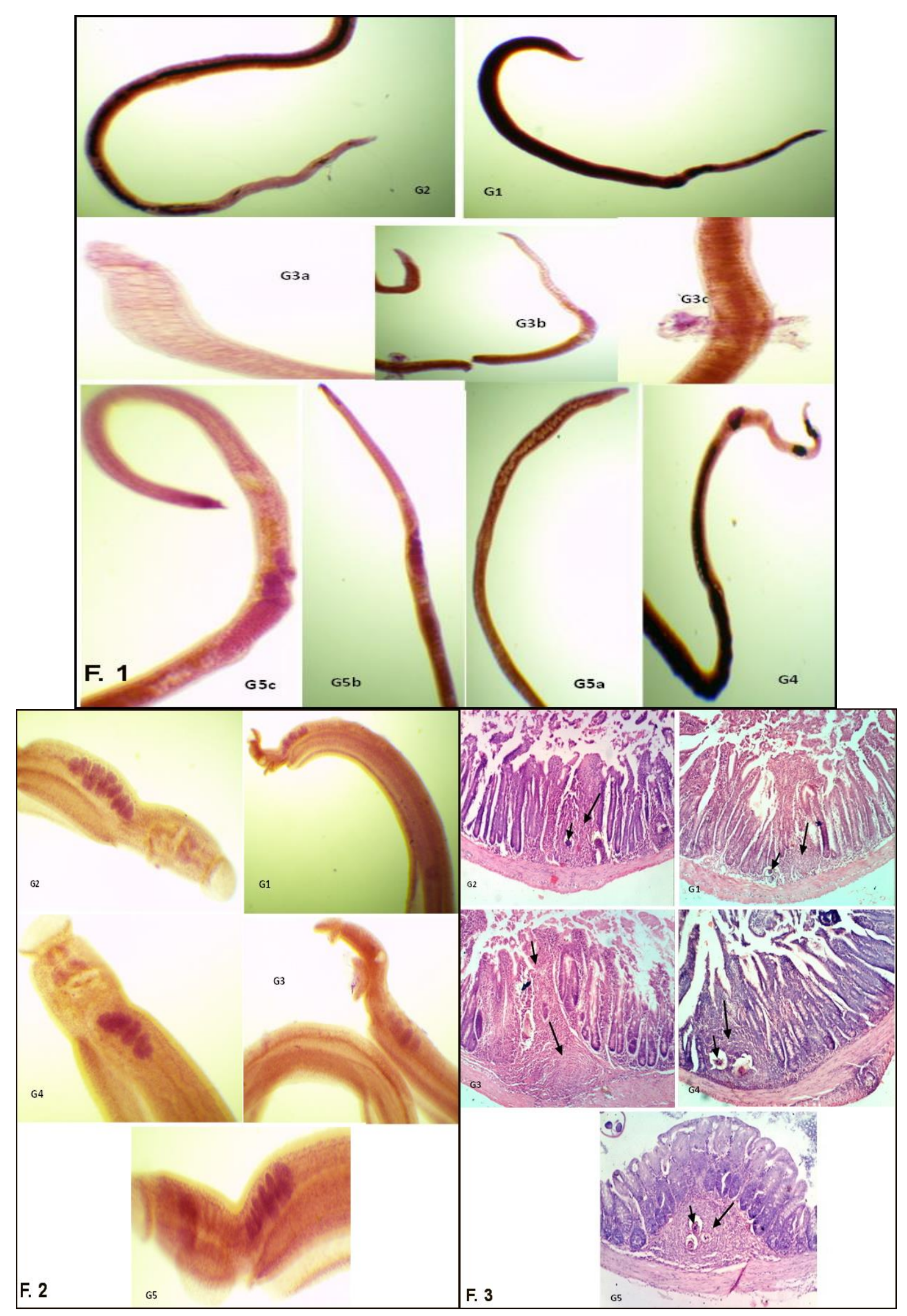



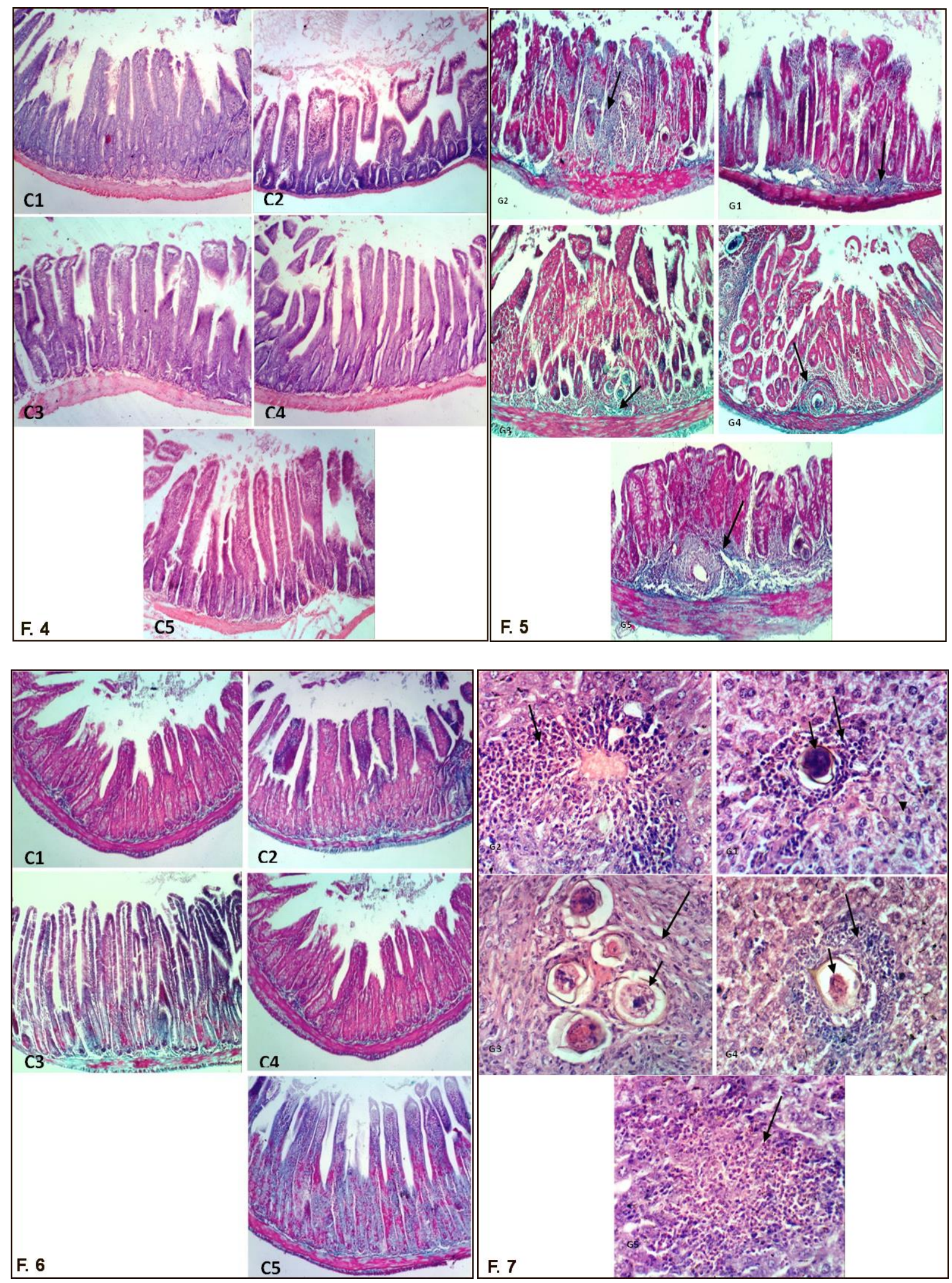


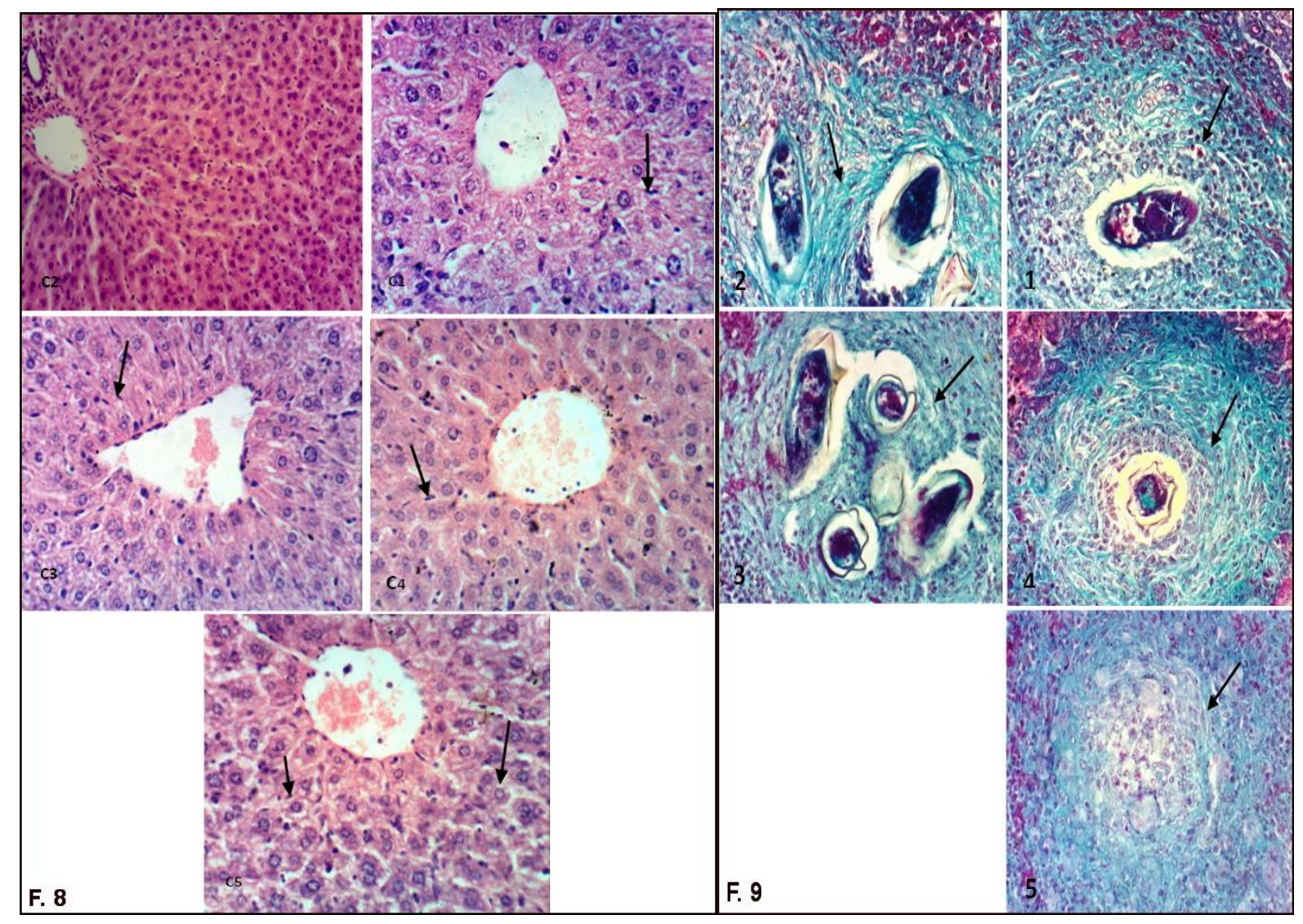

